\title{
Concurrent Manufacturing System Optimization for Two-Product Operation
}

\author{
George M. Bacioiu and Zbigniew J. Pasek \\ Industrial \& Manufacturing Systems Engineering \\ University of Windsor \\ Windsor, Ontario N9B 3P4, Canada \\ bacioiug@uwindsor.ca; zjpasek@uwindsor.ca
}

\begin{abstract}
Product/process design and optimization are typically aimed at a single product for a single customer. Such approach, however, often leads to underutilization of available production capacity. It is therefore reasonable for the manufacturer to make an effort to minimize available excess capacity to improve overall facility performance. Excess capacity can be allocated to the production of another product/process design, which can be also independently optimized. However, exploring possible synergies between the two products/processes may bring higher benefits.

This paper presents a case where a manufacturing process (plastic blow moulding) was shared among two different products for two different customers, each with a different set of needs. These customer needs were mapped into core value-creating processes, recognizing both the differences in their requirements as well as the similarities in their expectations. Conflicting differences in complexity, production volumes and quality requirements were reconciled using QFD_based approach, and led to improved customer satisfaction and cost performance.
\end{abstract}

\section{Introduction}

Quality Function Deployment (QFD) has been used extensively in the last few decades to create logical connection between the Voice of the Customer (VoC) and Process Parameters $[1,8,9]$. Typical steps in the process involve systematically defining $\mathrm{VoC}$, Critical to Satisfaction (CTS) elements, Functional Requirements (FR), Design Parameters (DP) and Process Parameters (PP). By consistent use of QFD, many companies have successfully achieved dramatic reduction of the Product Development cycles while simultaneously increasing the customers' satisfaction, $[6,7]$.
Common use of QFD methodology is focused on a development process for a single, individual product, typically carried out by a design-oriented unit. The details related to manufacturing of a product are passed on to be worked out either in a manufacturing unit of the OEM enterprise, or to a supplier. In the case of a supplier, it is rather rare, however, for a company to have only one, single OEM customer, or to have the resources to deal independently with multiple customers. To thrive and survive in today's markets, the supplier companies need to continuously maximize the use of available resources while maintaining high quality standards. In such a context one has to consider whether the QFD can assist not only with the single product development, but also to deal with development of a product portfolio.

The approach was based on a thorough search for the common operating range to fulfill entirely multiple sets of customer expectations, under assumption that an overlap existed. It explores QFD and other concepts in resolving conflicts between multiple customers that have different needs to be addressed simultaneously in order for the supplier to be competitive [6,8]. Primary challenging issue was to address the issue of coupling or decoupling the simultaneous fulfilment of the needs of different customers.

\section{Motivational Case}

The manufacturer of automotive products $\mathrm{C}_{0}$ supplies directly to two different customers, each of whom is targeting different part of the market: $\mathrm{C}_{1}$ aims at luxury segment, while $\mathrm{C}_{2}$ focuses on high volume/low cost segment. These customers have very different requirements: $\mathrm{C}_{1}$ emphasizes the quality of the product and timely delivery, while $\mathrm{C}_{2}$ 's focus is first and foremost on cost reduction and diversity of the product (which has two versions: I4 and V6). All of the entities (customers) compete for the same pool of resources.

Initial design of the manufacturing system is shown in Fig. 1. The key element, a blow moulding 
machine (BM) is common for two processes for two customers. Parts exiting from the BM are transferred to one of two process branches, or down-lines (DLs) by a shared gantry system; the two processes do not run concurrently. This design developed with capital investment savings in mind, however, imposes high requirements on scheduling, and on control and management of the lines.

When running, the system delivered very inconsistent results: the average scrap rate was over $20 \%$ (see embedded chart in Fig. 1). That is an extremely high level when compared not only to outside competitors, but also to other Value Streams in the plant. The delivery was also very poor requiring repeatedly expedited shipments to the customers due to the shortage of parts.

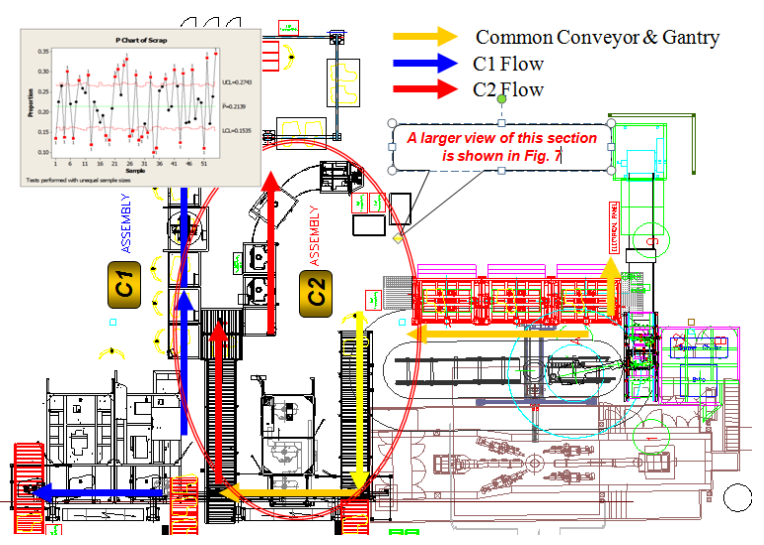

Figure 1. Initial System Design with the Scrap P-Chart

\section{Quality Function Deployment Analysis}

Quality Function Deployment [1] "provides specific methods for ensuring quality throughout each stage of the product development process, starting with design. In other words, this is a method for developing a design quality aimed at satisfying the consumer and then translating the consumers' demands into design targets ..."

\subsection{Defining Customer Requirements (CR) and Critical to Satisfaction (CTS) Criteria}

The analysis of customer (OEM) requirements allowed to cluster them in three major categories: Cost, Quality and Delivery (see Fig. 2).

In-depth analysis followed not only in identifying the Critical to Satisfaction criteria, but also in benchmarking the plant performance against Best-InClass. The first part of analysis, House of Quality 1 (HoQ1) is presented in Fig. 3.

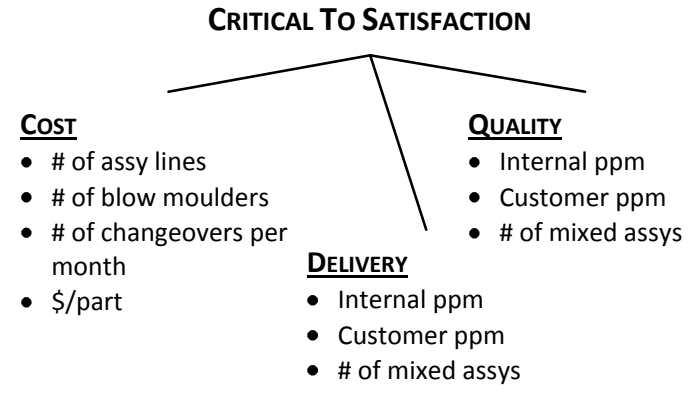

Figure 2. Critical to Satisfaction Criteria in Production

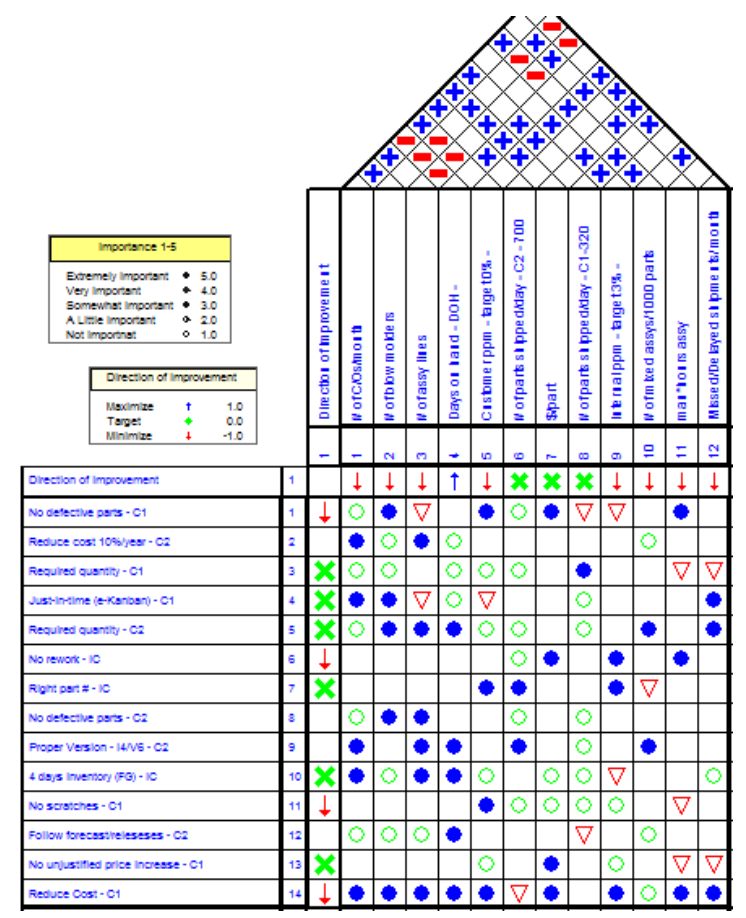

Fig. 3 - House of Quality 1 (HoQ1)

According to the analysis of HoQ1, customer requirements differ considerable between $\mathrm{C}_{1}, \mathrm{C}_{2}$ and $\mathrm{C}_{0}$, in the following areas:

- Complexity levels of $-\mathrm{C}_{1}$ has $75 \%$ more components then $\mathrm{C}_{2}$,

- Production volumes $-\mathrm{V}_{\mathrm{C} 2} / \mathrm{V}_{\mathrm{C} 1}=2$,

- Cycle times $-\mathrm{T}_{\mathrm{C} 1} / \mathrm{T}_{\mathrm{C} 2}=1.5$,

- Quality requirements $-\mathrm{Q}_{\mathrm{C} 1}>\mathrm{Q}_{\mathrm{C} 2}$,

- Delivery $-\mathrm{C}_{1}$ expects just-in-time (JIT), while $\mathrm{C}_{2}$ is forecast based.

\subsection{From CTS to Functional Requirements (FR)}

In the second part of analysis, House of Quality 2 (HoQ2) was constructed (see Fig. 4). The conclusions that can be drawn are the following: 
- The order of importance of FRs is very similar to CTSs and VoCs: Quality, Delivery and Economies of Scale. The challenge, however, is that unlike in a traditional balancing of a tripod - Quality, Delivery \& Cost -each "conflicting" CTS has a different customer behind,

- Economy of scale conflicts once again - as seen in the "roof" of the house - with requirements related to Quality \& Delivery.

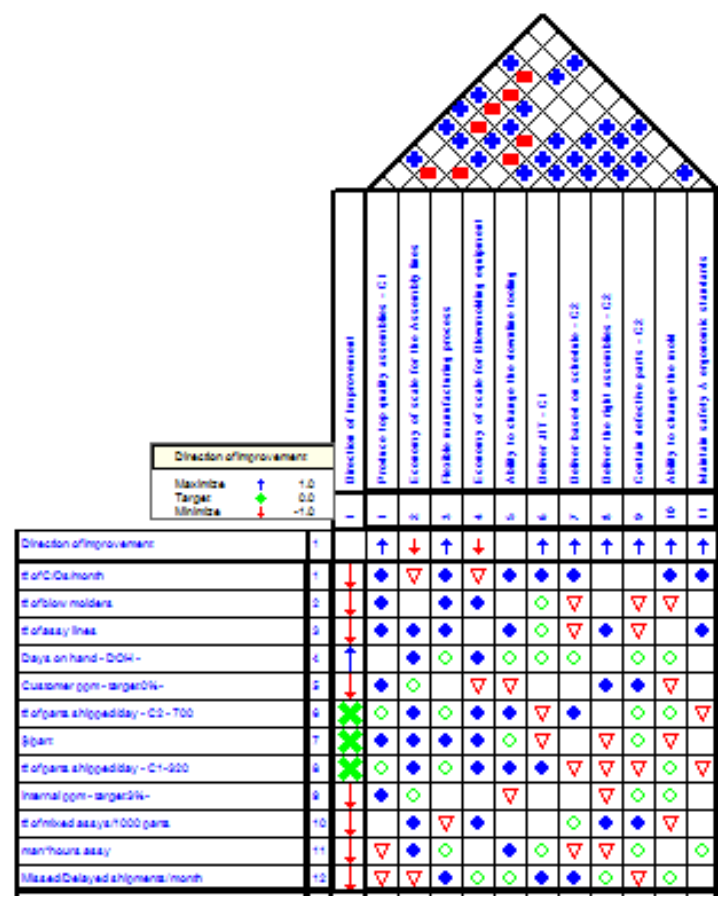

Fig. 4 House of Quality 2 (HoQ2)

\subsection{From FRs to Design Parameters (DPs)}

Based on House of Quality 3 (HoQ3) shown in Fig. 4, the following conclusions were drawn:

- The two most important design parameters (DPs) based on the previous analysis are: Two-way communication \& Management System and Independent Value Streams (VS) - e.g. design independently the VS for $\mathrm{C}_{1}$ from the VS for $\mathrm{C}_{2}$

- In the "roof" of the HoQ3 - the contradiction area - one can clearly identify the main conflict between the independent Value Stream design and the requirements related to Cost - very important to both, $\mathrm{C}_{2} \& \mathrm{C}_{0}$,

- The final design needs to consider all the conflicts identified throughout the QFD development and either eliminate them or minimize their adverse effects.

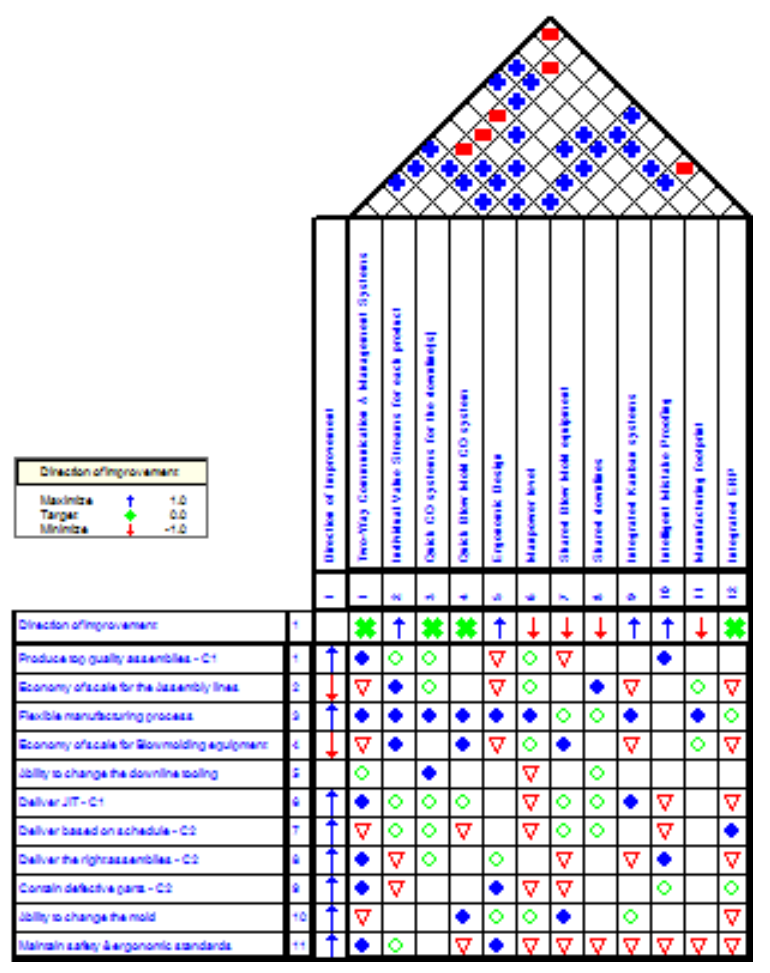

Fig. 5 House of Quality 3 (HoQ3)

\section{Developing Design Concepts}

Based on the QFD analysis, six new design concepts have been developed attempting to meet all the customers' requirements. A summary of the designs is shown in Table 1.

\section{Table 1. Summary of Designs}

\begin{tabular}{|c|c|}
\hline Design & Concept Summary \\
\hline Datum & $\begin{array}{l}\text { Integrated BMs - Partially coupled DLs } C_{1} \text { and } \\
C_{2} \text {, Coupled DLs } C_{2}-14 \text { and } C_{2}-V 6\end{array}$ \\
\hline 1 & Independent value streams: $C_{1} / C_{2}-14 / C_{2}-V 6$ \\
\hline 2 & $\begin{array}{l}\text { Integrated } \mathrm{BM}-\text { Independent } \mathrm{DLs} \mathrm{C}_{1} / \mathrm{C}_{2}- \\
14 / \mathrm{C}_{2}-\mathrm{V} 6\end{array}$ \\
\hline 3 & $\begin{array}{l}\text { Independent } \mathrm{BMs}-\text { Independent } \mathrm{C}_{1} \text { - Coupled } \\
\mathrm{DLs} \mathrm{C}_{2}-14 \text { and } \mathrm{C}_{2}-\mathrm{V} 6\end{array}$ \\
\hline 4 & Independent BMs - Coupled DLs $\mathrm{C}_{1}$ and $\mathrm{C}_{2}$ \\
\hline 5 & Integrated BM - Coupled DLs $\mathrm{C}_{1}$ and $\mathrm{C}_{2}$ \\
\hline 6 & $\begin{array}{l}\text { Integrated } \mathrm{BMs}-\text { Independent } \mathrm{C}_{1}-\text { Coupled } \\
\text { DLs } \mathrm{C}_{2}-14 \text { and } \mathrm{C}_{2}-\mathrm{V} 6\end{array}$ \\
\hline
\end{tabular}

The Datum (reference) against which all of the proposed new designs were evaluated is the initial (existing) design: Integrated BMs, coupled $\mathrm{C}_{1}$ and $\mathrm{C}_{2}$ 
and, within $\mathrm{C}_{2}$, coupled down-lines (DL) C2-I4 and C2-V6. The initial design was chosen without consideration whether it satisfies all the main elements required to meet the VoCs. The outcome of comparison of designs under consideration was summarized in a Pugh Matrix (see Fig. 6).

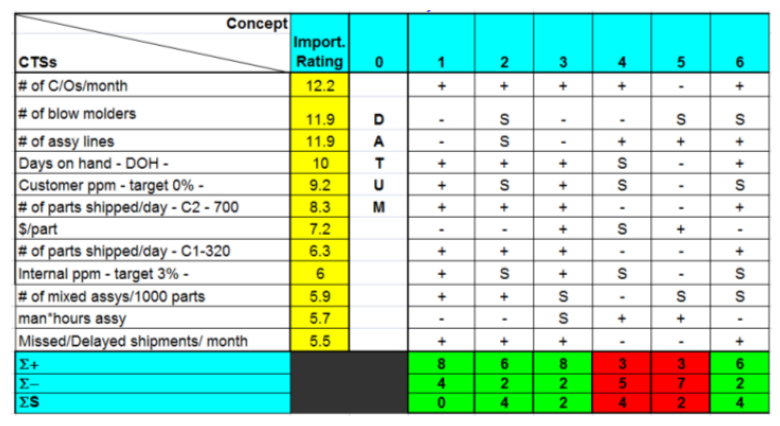

Fig. 6 Pugh Matrix

Based on the Pugh Matrix analysis one can conclude the following:

- There is no "perfect" design as the three customers have very divergent requirements, which cannot be fully reconciled,

- 4 out of the 6 proposed designs offer better solutions then the Datum,

- The 2nd best design (D1), which is $100 \%$ Independent VS, meets most of the $\mathrm{C}_{1} \mathrm{C}_{2}$ requirements, but is unacceptable to $\mathrm{C}_{0}$ due to the very high capital investment cost associated,

- The best design (D3) Independent BMs, independent DLs $\mathrm{C}_{1}$ and $\mathrm{C}_{2}$ and coupled C2I4 and $\mathrm{C} 2-\mathrm{V} 6$ - is a fair compromise between the 3 opposite requirements;

\section{Selected Solution}

The situation required a return to the drawing board and a complete redesign of the production lines. A compromise design (D3) where the BM is shared but the two external customers are completely decoupled was selected. Even if the chosen re-design was not the best (according to the requirements), decoupling completely the assembly down-lines should significantly improve the business metrics.

To facilitate the decoupling, process improvement was conducted to increase its flexibility through the following objectives:

- Reduce the travel of the operators,

- Re-program the welder, a key piece of equipment in the assembly of the parts,

- Replace automatic scanners with manual,
- Introduce a new mistake-proofing station to reduce the rework for $\mathrm{C}_{2}$,

- Re-balance the line so the manpower does not change with the introduction of the new station,

- Open a logical gate at the back of the feeding conveyors to improve the flow, $[3,4]$.

Table 2 Constraints Reduction Chart

\begin{tabular}{|c|c|c|c|c|c|}
\hline & \multicolumn{2}{|c|}{ Old } & & \multicolumn{2}{|c|}{ New } \\
\hline & $\mathrm{C}_{2}$ & $\mathrm{C}_{1}$ & Action & $\mathrm{C}_{2}$ & $\mathrm{C}_{1}$ \\
\hline \multirow[t]{2}{*}{ BM } & 0 & 0 & $\begin{array}{l}\text { Add quick-change } \\
\text { tooling }\end{array}$ & $\odot$ & $\odot$ \\
\hline & $\mathrm{O}$ & $\mathrm{O}$ & $\begin{array}{l}\text { Add independent out } \\
\text { feed conveyer for } \mathrm{C} 1\end{array}$ & 0 & $\bullet$ \\
\hline \multirow[t]{2}{*}{ Weld } & $\mathrm{O}$ & $\mathrm{O}$ & $\begin{array}{l}\text { Split gantry to allow } \\
\text { independent } \mathrm{C} 1 / \mathrm{C} 2 \\
\text { welder operation }\end{array}$ & - & $\bullet$ \\
\hline & $\mathrm{O}$ & $\mathrm{O}$ & $\begin{array}{l}\text { Change C1 welder to } \\
\text { offline operation }\end{array}$ & $\mathrm{O}$ & $\bullet$ \\
\hline Assy & - & - & No change & - & - \\
\hline
\end{tabular}

Table 2 shows the reduction of the design constraints by decoupling the DLs. The re-design is identical with Design 2 in the Pugh Matrix (Fig. 6). The BM is still shared - that is contrary to the best identified design - as well as the DLs for $\mathrm{C}_{2}$ - this time the decision is aligned to the best $\mathrm{D} 3$ solution.

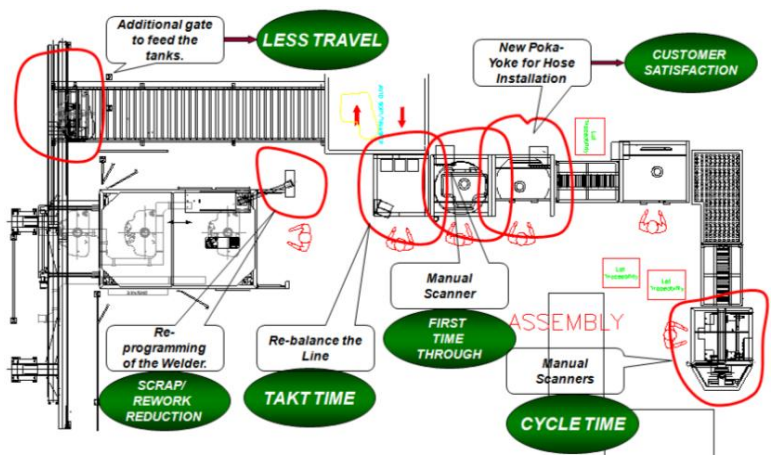

Fig. 7 - Process modifications on $\mathrm{C}_{2}$

\subsection{The New System Layout}

The major change in the new design stands in the decoupling of the two assembly lines: $\mathrm{C}_{1}$ and $\mathrm{C}_{2}$. Beyond the fundamental improvements identified by the Pugh Matrix, additional benefits turned a very problematic manufacturing process into an acceptable one that carried on the production until customer $\mathrm{C}_{2}$ 
discontinued its product. Some of the technical and management improvements are listed below:

- A logical gate was designed and installed at the end of the input conveyor after the BM Fig. 7. That allowed a better management of the production - e.g., in case of assembly issues down the line the shells were recuperated and introduced back once the assembly line issues were solved; An expansion/contraction study was required in order to validate the reuse of the unfinished product,

- Customer C1 was relocated in such a way that access from both sides was provided to the Associates; That solved many of the production issues, allowing a more efficient distribution of work as well as easier access to replenish the inventory, [5],

- Incremental steps were taken towards improving both assembly lines from the flow as well as safety \& ergonomics perspective,

- Major improvements that enabled better scheduling based on customer demand was change over reduction on the BM.

\subsection{Improved Performance}

Fig. 8 shows the significant reduction in the scrap level generated by the BM from over $20 \%$ to below $1 \%$. All the system modification mentioned previously contributed to the improved performance. Fig. 8 clearly shows a positive trend throughout the improvement cycle. A significant improvement occurred in the number of parts produced from an average of about 525/day to over 650/day (24\% increase).

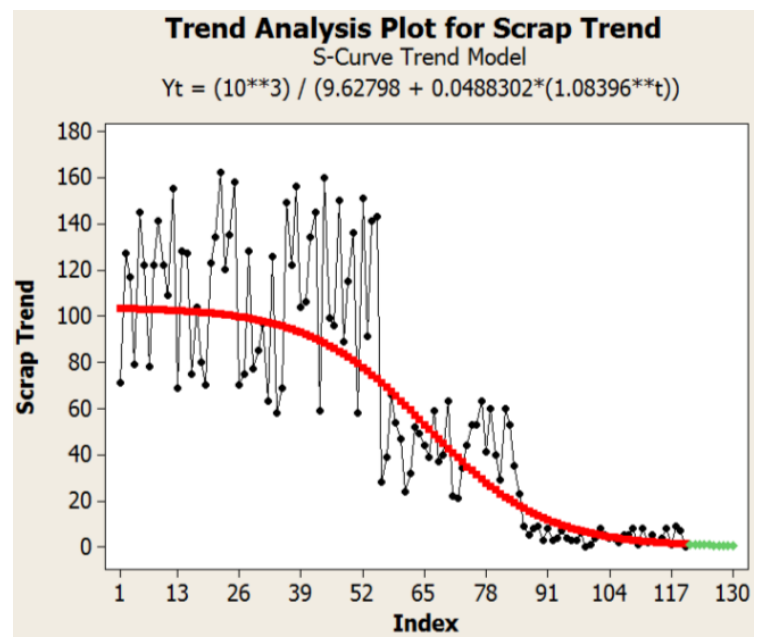

\section{Summary and Future Work}

This paper presented an approach that allows a company to resolve conflicts between multiple customer requirements over a wide range of needs. It is based on concurrent use of concepts traditionally applied in Process/Design Optimization. The approach was tested on a real manufacturing process and led to significant improvements. While an ideal solution might not be always possible, by applying the concepts presented in this paper companies could resolve either entirely or partially the conflicts generated by multiple customers requiring access to a limited pool of resources. The approach combines three perspectives: Business, Design and Process, in challenging decision making under the simultaneous fulfilment of the needs of different customers.

Future efforts are aimed at verifying feasibility of the approach in other applications, such as, for example, healthcare, food manufacturing, retail etc.

\section{Acknowledgments}

Authors want to express their gratitude to the management of Kautex Textron for the access to production data and facility.

\section{References}

[1] Y. Akao, Quality Function Deployment: Integrating Customer Requirements into Product Design, Productivity Press, 2004.

[2] J. Neter, J et al., Applied Statistics, 3rd Edition, Allyn and Bacon, Inc., 1988

[3] R. Hayes, R et al., Strategic Operations, Competing Through Capabilities, Harvard Business School Press, Boston, 1996

[4] R. Schonberger, World Class Manufacturing: The Lessons of Simplicity Applied, The Free Press, 1986

[5] S. Chengalur, S. et al., Kodak's Ergonomic Design for People at Work, John Wiley \& Sons, Inc., 2004

[6] J. Michalek, "Preference Coordination in Engineering Design Decision Making," Doctoral Dissertation, Mechanical Engineering, University of Michigan, Ann Arbor, 2005

[7] C. Adiano, V.A. Roth, Beyond the House of Quality: Dynamic QFD - University of North Carolina, Chapel Hill, North Carolina, USA -, No. 1, 1994, pp. 25-37. MCB University Press, 1351-3036

[8] Prasad, B. - Review of QFD and Related Deployment Techniques - Journal of Manufacturing Systems Vol. 17/No. 3, 1998

[9] Y. Akao, G.H. Mazur, The Leading Edge in QFD: past, present and future - Asahi University, Tokio, Japan, 2003

Fig. 8 Trend analysis 